\title{
Childhood Spaces in a Changing World: exploring the intersection between children and new surveillance technologies
}

\author{
TONYA ROONEY \\ Faculty of Education, University of Canberra, Australia
}

\begin{abstract}
Children are at the forefront of the rapidly changing technological landscape, living in a world where both physical and virtual spaces are an intertwined part of daily experience. As an example of a child's changing relationship with new technologies, this article explores the increasing presence of surveillance technologies in the day-to-day spaces children inhabit. It suggests that childhood experience needs to be understood in the context of fluid and interdependent relations with others and the worlds around them, including their relationships with new technologies in the surrounding environment. At the same time, it is important to retain a view of the child that is more complex than what is simply gleaned through their relationship with new technologies, even as this becomes a prominent mode of interaction with others and the world around them.
\end{abstract}

For children in many societies, new technologies are increasingly part of everyday life. The changes are such that we are continually being challenged to rethink the relationship between children and emerging technologies, and what this means for contemporary childhood experience. This article explores the intertwined physical and virtual worlds that children now inhabit, with a focus on the increased presence of surveillance technologies in the spaces children move about in. Of particular interest is the type of knowledge that is produced through surveillance of children using new technologies, and the risks that may arise if these are considered in isolation or independently from a child's broader lived experience and relations with others.

In this article, I will first of all consider the changing role of new information technologies in children's lives, and how technologies that are used as tools of surveillance are increasingly part of this change. I then turn to emerging theory on surveillance and new technology, drawing on the concepts of the 'surveillant assemblage' and the 'data double' (Deleuze \& Guattari, 1988; Haggerty $\&$ Ericson, 2000) as ways of understanding the new dimensions surveillance technologies bring to a child's experience of the world around them. Finally, I aim to show that, contrary to the motivations that underlie many uses of surveillance technologies, there is no single, static, independent notion of child that is potentially 'knowable' as an object of surveillance. Furthermore, the use of surveillance records is far from neutral, but rather reflects the power dynamics at play in managing and controlling the lives of children, often in the context of wider social and political interests. Problems arise if surveillance records are used in a way that limits what is 'known' about a child to a static and partial perspective, while at the same time portraying this as in some sense the 'truth' of what there is to know of the child or situation. This is because the politics of control behind these practices are likely to act to reinforce the values and perspective of those undertaking the surveillance in a way that disregards the interests or perspective of the child.

Overall, this analysis aims to contribute to a better understanding of the complex nature of the emerging physical-virtual world that children find themselves in and, at the same time, highlight the potential risks that arise if surveillance technologies are used in a way that renders 
invisible the very nature of this complexity and its place in a child's emerging sense of self and in how we come to know the child. This discussion also aims to contribute to wider discussions on contemporary childhood experience by highlighting some reasons why the physical and virtual domains of a child's experience need to be considered as an intertwined part of the landscape of that experience, rather than as two separate domains that impact on each other in fixed and definable ways. The scope of the article is generally focused on children from birth through to the primary years of school (around 12 years of age). While many of the issues raised have an impact beyond this period, and even into adulthood, the aim here is to highlight the implications of the changing technological landscape from the very earliest years when a child is developing an understanding of others and the world around them. It is acknowledged that this will not reflect the experience of children in all societies. However, what can be observed is that, globally, we are witnessing an unprecedented growth in the use of technologies, and so the discussion here potentially applies to a wide and diverse range of childhood experiences.

\section{New Technologies as Part of Children's Lives}

The changes brought about by technologies in the twenty-first century extend our capacity to communicate and interact with others in ways that challenge our very understanding of what it is to be human. They do this by extending our perceptual reach beyond our immediate physical environment, thereby changing the way we come to understand the world around us (Cleland, 2010, pp. 75-76).

Young children growing up in a digital world are immersed in a range of new technologies from birth that are increasingly part of how they engage and interact with the world around them (Marsh et al, 2005; Yelland, 2007; Plowman et al, 2010). It is becoming difficult to separate a child's immediate, physical experience of others and the world around them from virtual and technological domains of experience. As an example, young children increasingly participate in social networking sites. In 2011, it was estimated that half of all children aged 6-12 in the United Kingdom, Australia and New Zealand owned a virtual 'Moshi Monster' (Independent, 2011), while Club Penguin (targeting ages 8-11) boasts 150 million accounts across 190 countries.[1] Other online audio-visual communication tools, such as Skypito - a program similar to Skype designed specifically for use by children aged 2-14 - are becoming more widely used as technology becomes cheaper and more accessible.[2] Add to this the growing use of mobile technologies via mobile phones, tablets and gaming devices, and it is possible to see how the lives of children are increasingly immersed in a blended physical and virtual landscape.

While the presence of new technologies represents a significant change in the spaces of a young child's experience, children themselves do not necessarily see this as a uniquely defining feature of their day-to-day life, with new technologies being only one of many parts of their rich fabric of experience (Plowman et al, 2010, p. 18). At school, the use of the Internet is viewed by children as not only a learning tool, but a social space too: 'The wired child is not an isolated child or technical entrepreneur, but a child who has integrated the Internet fully into his or her social life' (Steeves, 2010, p. 88). By the time many children reach late primary school, online tools such as instant messaging, chat rooms, webcams, blogs and social networking sites have become critical in their social life (Mishna et al, 2009).

In such an environment, it would be overly simplistic to try to understand how a particular technology might impact on a child if both the technology and the child are only understood as non-changing, stable entities that are somehow isolated from each other and from the context and connections around them. As Prout (2005, p. 125) suggests, the 'effects' of new information and communication technologies are unlikely to 'fold into childhood in any simple or uncontested way', but rather they extend children's reach into new worlds that multiply the potential of the temporal and physical boundaries of their day-to-day lives.

There is much debate about what the increasing immersion in new technologies means for the lives of young children. Some express concerns about the implications for a child's development if interaction with others is impacted by excessive screen time (American Academy of Pediatrics, 2011) or if children become increasingly disconnected from the natural world (Louv, 2005). Others explore the creative potential for young children's learning that is opened up by 
interactive and digital technologies (Yelland, 2007), and the need for educational practices to better reflect the importance of media and new technologies in children's lives (Marsh et al, 2005). One dimension that is increasingly evident is the creativity and competence children bring to the use of new technology and new media (Valentine, 2000; Buckingham, 2007), with some also noting the potential of these to provide alternative virtual spaces for creative play (Aitken, 2001, p. 178), allowing children a chance to bring their own interpretation and meaning to new spaces.

This article explores a child's changing relationship with new technologies by exploring the specific use of these as tools of surveillance. It does this by considering the changes that surveillance technologies bring to the spaces of childhood experience. These spaces need to be understood as not simply empty and neutral expanses where activity takes place. Rather, spaces are conceived as having a political dimension that shapes the social interactions and activity within them (Lefebvre, 1991, quoted in Monahan \& Torres, 2010, p. 8). In turn, spaces themselves are constantly being shaped and recreated by the social relations within them (Massey, 2005, p. 152). All activity within a space is in some way subject to the forces of power, conflict and inequality that are present. Whether children are playing in a park or chatting via a social networking site, they are part of this ongoing process of working out how to interact with others, of activity and exploring possibilities. At the same time, this is happening within a space that is socially regulated in some way through various types of controls and ongoing negotiations around the rules (whether implicit or explicit) that might apply within that space (Massey, 2005, pp. 152-162). A child's creative potential is determined not just by their own skills, choices and actions, but also by their relations with others and the natural world, with technologies and the multiple social forces that shape and continually transform the spaces they move about in.

The presence of surveillance technologies in a space arguably constitutes one of the more explicit forms of social and political control that children encounter in merged virtual-physical spaces. As will be discussed below, there are various relations of power that shape our ways of coming to know the child and how the child, in turn, comes to understand themselves and others. It is important to explore the risks of placing too much emphasis on coming to 'know' the child through what surveillance technologies tell us about the child, as this potentially increases the vulnerability and passivity of the child in an environment where they might otherwise have the potential to thrive as creative and competent beings.

\section{Technologies as Tools of Surveillance: an increasing presence in children's lives}

Practices of observation and recording are an integral part of children's lives, ranging from the various ways that families share information about children's lives (such as through storytelling and photographs), to the more formalised ways specific records are used in professional practice, such as in heath, school and childcare settings. While the concepts of observation and surveillance are closely interrelated, the approach taken here is to understand the practice of surveillance as an activity that involves some combination of watching, listening or observing, generally for the purpose of monitoring and control. There is generally an intention to influence or control the object of the surveillance in a purposeful and systematic way (Lyon, 2001; Ball et al, 2006).

Many new information technologies open up opportunities for observation and collection of data which had, until recently, not been possible. For example, new technologies now make it possible to collect more detailed information by continuously recording information without having to be physically present and by allowing multiple viewpoints to be captured. There are new forms of data that can be collected, such as genetic and biometric data, including digital forms of these that may be collected via facial recognition, body scanning or fingerprinting systems. Location trackers (such as the Global Positioning System, which relies on satellite technology to determine a particular location, and radio frequency identification technology), closed-circuit television (CCTV) cameras and a range of swipe card, database and microchip implant technologies are also part of the range of technologies that may be used as tools of surveillance. To talk of 'surveillance technologies' is therefore to refer to information technologies that have the potential to act as tools of surveillance by recording, scanning, listening to and watching activities, people or spaces. At the same time, these records bring with them the potential for control through communication, collation or manipulation of the data records. 
Traditionally, surveillance has been associated almost entirely with institutional or state power over its (less powerful) citizens, and has been a practice more prominent in the public, rather than the private, domain. However, as the examples below illustrate, this view of surveillance is no longer sustainable in a world where new technologies bring new potential for power into the hands of individual citizens, as well as government and business. The examples also show how these technologies may act to blur the boundaries between public and private lives.

Technologies of surveillance can target children directly or indirectly if children happen to be in a space where surveillance (such as CCTV) is present. In the home, examples of these technologies include the use of baby monitors - some with two-way video and audio capacity - as well as hidden 'nanny cams' embedded in everyday objects such as teddy bears and tissue boxes.[3] While it is difficult to measure the exact growth in the use of these technologies, companies report that sales continue to increase (McClure, n.d.).

Outside the home, there is an increasing use of CCTV cameras in schools and webcams in childcare centres. While more research is needed in this area, a recent survey in the United Kingdom showed that up to $85 \%$ of schools have CCTV cameras (Taylor, 2010). Cameras continue to be installed in both existing and new schools in many other countries, and webcams are now often used as a marketing tool to promote the safety credentials of childcare centres.[4] Tracking devices, such as those embedded in children's clothing or mobile phones, are another form of surveillance that parent's might use (Luckerson, 2012).[5]

Another example of changing surveillance practices applied to children is the growth in largescale government databases to record details such as education, behaviour, health and risk indicators for children from birth to when they leave school. Since 2002 in the USA, the No Child Left Behind policy has required widespread assessment of students against a standards-based curriculum. The result is not just educational policy in practice, but a surveillance tool that favours certain practices and, some argue, brings changes to the classroom, as teachers 'teach to the test' (Gilliom, 2010, p. 197). The Australian government has conducted the National Assessment Program - Literacy and Numeracy (NAPLAN) tests since 2008 on students in various years of primary and high school. The purpose of the test is to measure whether or not young people have the literacy and numeracy skills required to participate as productive members of society, and to measure the effectiveness of teaching programs (Australian Curriculum Assessment and Reporting Authority, 2011). While debate continues on the immediate impact and value of this testing program for students and teachers (Stevenson, 2012), what also remains unclear is the full scope of future potential uses of this data. For the discussion here, a key point to note is that the individual data that populates the database can only ever be partial and the room for error is likely to be high (Athanasou, 2010).

Some of the examples mentioned above (such as baby monitors and tracking devices) show how surveillance technologies used on children are marketed or conceived as tools of 'care' - that is, the motivation for parents to use surveillance may not be a desire for discipline and control, but rather for safety or protection of the child. Whether this represents an appropriate or an overreactive response to 'caring' for children is the subject of much recent debate on balancing risk and safety in children's environments (Katz, 2006; Malone, 2007; Rooney, 2010). What can be seen is that with the shift towards surveillance as a practice of 'care' in children's settings, the distinction between control and care is becoming more blurred and ambiguous, as these new forms of care also bring with them new opportunities for control.

There are other ways in which the practice of surveillance and other forms of information collection are becoming increasingly blurred. The growth in sharing information via social networking sites, and the uploading of photographs and videos to sites such as Facebook or YouTube, adds to the normalisation and acceptance of this practice. While these examples might not necessarily be considered forms of 'surveillance' as such, they act to blur the boundaries by using technologies in ways that have the potential to enable new forms of control, even as they open up creative new forms of expression (Koskela, 2004).

The online sharing of photographs and videos of children is another part of this trend. A survey in 2010 by Internet security company AVG of 2200 mothers in North America, Europe, Australia, New Zealand and Japan found that $81 \%$ of children under the age of two currently had some kind of digital profile or footprint, with images of them posted online. The survey also showed that almost one-quarter (23\%) of children begin their digital lives when parents upload 
their prenatal sonogram scans onto the Internet (Business Wire, 2010). Details about children's lives are therefore increasingly shared and available across global virtual spaces in new and groundbreaking ways. Children may drive or initiate some online content about themselves, but much is also generated without their knowledge or input.

Even if it is difficult at times to disentangle the surveillance element of this changing landscape, the desire to control, shape, discipline or keep tabs on the child is still very much part of the increasing surveillance over children's lives. Furthermore, this trend is consistent with the attempts (whether by families, communities or governments) to control the various 'risks' associated with childhood. The understanding of childhood - in Western societies at least - has undergone a significant transformation in recent times, and much of this can be attributed to the emerging notion of childhood as vulnerable and 'at risk' (Nadesan, 2010, p. 2). Furthermore, there are cultural and political practices that have led to childhood now being seen as 'a problem space requiring careful surveillance, deliberate cultivation and expert guidance' (Nadesan, 2010, p. 19). This characterisation of children as 'at risk' can be seen in contemporary attitudes to children. Public spaces are often viewed as spaces to 'fear' (Valentine, 2004, p. 15) and, in schools, there is evidence that risk anxiety now pervades school playgrounds, placing additional pressure on teachers to protect children (Freeman \& Tranter, 2011, p. 61).

While it is, of course, important to protect children, there is evidence that the practices of control over children's spaces are now far in excess of any realistic assessment of risk (Monahan $\&$ Torres, 2010, p. 1). The notion of risk is therefore more a social and political construction of the child as somehow vulnerable and in danger. The expanding range of surveillance products described earlier is evidence of companies' willingness to capitalise on and reinforce the 'risk' and 'fear' discourse that surrounds contemporary childhood.

One of the consequences of understanding childhood as fraught with risk (and also seeing some children themselves as 'risky') is that society then acts to develop strategies of control to address those risks. This approach is inevitably shaped by inequalities in our social and political system - such as those based on class, race and gender - rendering an uneven application of methods of control for different children (Lyon, 2003, p. 7; Monahan \& Torres, 2010, p. 7). CCTV cameras that capture information in school playgrounds or government databases that collate extensive information on children's learning and behavior do not therefore operate in a politically neutral vacuum, but rather become part of the technologies of power that seek to control and manage children's lives (Monahan \& Torres, 2010; Nadesan, 2010).

\section{Theorising the Contemporary Surveillance Landscape}

The complexity introduced by new types of technologies is changing the ways we think about the practice of surveillance. One of the most influential and enduring models of surveillance is Bentham's panopticon. This model is based on a design for a prison, with a central watchtower surrounded by a cylindrical structure which contains the prison cells, such that the guards can see into every cell without themselves being seen. The underlying principle is that those being watched must never know when they are being watched, but they must know that this possibility is always present. This system, reinforced by a system of punishment, leads to individuals ultimately behaving as if they are under surveillance at all times, just in case the observer is looking at them (Bentham, 1995).

Foucault (1991, p. 202), in drawing on Bentham's concept of the panopticon, describes how the disciplining impact of surveillance can lead, eventually, to a self-disciplining effect - that is, the possibility of being watched can lead to a more permanent effect, where the individual starts to take on the constraints of the external watcher and alter their behaviour accordingly, even when they are not being watched. For Foucault (1991, p. 201), the effect of surveillance would reach its perfection when the exercise of power was no longer actually necessary. Surveillance can create an effect that is not just oppressive, but has a productive element, whereby it becomes part of how we construct ourselves (Haggerty \& Ericson, 2000, p. 607).

Both Bentham and Foucault remain key points of reference in considering the power dynamics at work when surveillance technologies are used. In recent times, some have suggested that the panopticon model cannot explain everything about the current surveillance environment 
and there is a need to move beyond this to explore other ways of thinking about surveillance (Lyon, 2006, p. 11). This is because surveillance practice now rarely involves a single technology used for a specific purpose by a particular institution. Rather, multiple technologies are used in ways that intersect and overlap with each other, and are often brought together in different configurations for a variety of purposes. A fingerprinting system might collect data, which is fed into a database then incorporated or cross-matched with other data collections, and then perhaps converted to a different format to be used elsewhere, and so on. What we are faced with, then, is a multilayered surveillance landscape shaped by a range of different forces and with the potential for interlinking and sharing information.

In addition, surveillance is no longer limited to situations involving institutional or state power over others. This is because, as mentioned earlier, surveillance technologies are no longer only within the reach of the government or law enforcement agencies, but are also in the hands of individuals and families: a mobile phone with the capacity to record, take photos, communicate, upload data to the Internet and be located to an exact physical position is one such example. This expands the range of power dynamics that are possible. Those in power are no longer outside the population who may be under surveillance, and we could potentially be subject to surveillance by our peers or family, as well as those in government or institutions.

It is these characteristics that lead Haggerty and Ericson (2000) to suggest that what were once discrete surveillance systems are now converging into what we can speak of as a 'surveillant assemblage'. Assemblages can be understood as a number of objects whose unity comes from the fact that they 'work' together. Contemporary surveillance practice, when understood as a 'surveillant assemblage', grows through expanding combinations and uses of surveillance technologies. Haggerty and Ericson note, however, that:

to speak of the surveillant assemblage risks fostering the impression that [they] are concerned with a stable entity with its own fixed boundaries. In contrast, to the extent that the surveillant assemblage exists, it does so as a potentiality, one that resides at the intersections of various media that can be connected for diverse purposes. (Haggerty \& Ericson, 2000, p. 609)

There is no central structure to a 'surveillant assemblage', but rather multiple connections made across many technologies. Driving these are multiple desires, such as desires for control, security, profit and entertainment, which exponentially increase the capacity for surveillance (Haggerty $\&$ Ericson, 2000, p. 609). This also means that there is no central point of power which could be targeted to undermine the practices of surveillance. Rather, there is a levelling of the power hierarchies such that there is no single, dominant institution in control of the surveillance forces at play (Haggerty \& Ericson, 2000, p. 614).

Although the notion of the 'surveillant assemblage' aims to take surveillance theory beyond the panoptic model, it is nonetheless possible to see elements of Foucault's analysis at play. Provided that the surveillance technologies act to produce the desired effect of making people believe and behave as if they are being watched, then the impact of the diffuse, less hierarchical and multidirectional gaze(s) on individual behavior is not dissimilar to the effects of panoptic power.

A key point of interest from the work on the 'surveillant assemblage' is what it reveals about the intersection between technology and the human body. Haggerty and Ericson suggest that, unlike earlier models of surveillance, the 'surveillant assemblage' does not approach the body as something to be punished or controlled (or at least not straight away), but rather as something that must at first become known. It does this by drawing on multiple records and flows of information about the body and reassembling these in a virtual sense across different settings to create a virtual 'data double'. This 'data double' then constitutes an additional self, which can be scrutinised and targeted for intervention (Haggerty \& Ericson, 2000, p. 606).

Surveillance, then, is more than watching; the observation is creative and constructs new, virtual versions of individuals (Gilliom, 2010, p. 205). The limitation is that these recreations only select certain pieces of data from what are highly complex individuals and activities. Consider a child engaged in an activity on a social website or online gaming where marketing practices are present as a key driver or influence. In contrast to coming to know the child as a complex, embodied and social individual, the marketing company's interest is more in selecting certain characteristics and demographics to capture in a database. What is captured is a virtual 'data double' of the child, reassembled from selected pieces of information collected from the child's 
online encounters with others. This abstracted, virtual individual is, to the marketers, potentially more 'real' than the human child in the sense that it becomes the version of the child that holds significance and meaning for marketing purposes. As I discuss shortly, the emergence of these forms of 'data double' has implications for how others come to know a child and also for a child's own emerging sense of selfhood.

Surveillance practices directed towards the human are therefore capable of producing 'data doubles' which are comprised of information about the individual and then reconstructed in certain ways. Surveillance is often directed towards the human body with the result that it is, first, "broken down by being abstracted from its territorial setting. It is then reassembled in different settings through a series of data flows. The result is a decorporealised body, a "data double" of pure virtuality' (Haggerty \& Ericson, 2000, p. 611).

One of the features highlighted by Prout (2005, p. 115) in his analysis of Deleuze and Guattari's work is that assemblages bring with them new ways of seeing how humans are connected with the world in a way that decentres what it is to be human: 'Human history is the process of borrowing from the non-human world, creating new combinations and new extensions of the body'. The virtual 'data doubles' of the self therefore result in a technological extension of the body, where the human is no longer at the centre of the constitution of personhood, but rather human and technology are intertwined in a way where each contributes to the constitution of the other.

\section{Spaces of Surveillance: implications for childhood experience}

While children's lives have always been subject to the multiple gazes of family, friends, carers and various others, it is the growing use of surveillance technologies over the spaces that children inhabit which has led to the rapid emergence of the 'data double' in a child's life. In order to understand the significance of the virtual or 'data' forms of a child's life captured via surveillance technologies, it is helpful to ask: What is different about a space because there is a surveillance technology operating over that space? So, for example, what is different about a child's experience of various spaces as they walk home from school without a tracking device fitted into their clothing, compared to this experience if they have such a device that records, or leaves virtual 'breadcrumbs' of, their journey home and allows their parents to view that journey over the Internet? In order to address this question, I discuss a number of features of what can be described as a 'space of surveillance', that being a physical or virtual space where there is a surveillance presence.

There are three points of difference highlighted here between a 'space of surveillance' and the equivalent space without a surveillance presence. In a space of surveillance, the activities in the space have a presence beyond the 'here and now'. Also, there is an observer of the space who is generally distant and non-interactive, and, finally, there are new forms of knowledge that emerge from the space. Considered individually, some of these features may exist in spaces not under surveillance. They are brought together here in an attempt to capture much of what a surveillance gaze might bring to a space.

The first feature is that the activity in a space under surveillance becomes no longer just an activity of the 'here and now'. Rather, individual actions can potentially have a presence or reality in other locations in space and time when surveillance records are viewed. Social activity is therefore being conducted in the presence of other(s) who are not 'there' in any physical (or sometimes temporal) sense. In this sense, surveillance introduces to a space the possibility of being viewed or listened to at other times and places by a range of unknown others, often in contexts far different to the original setting (Patton, 2000). It brings to the space the absent 'presence' of these potential others. One implication is that activity is no longer guaranteed to be a 'here-and-now' moment that slips into an unrecorded past. For the child walking home from school with a tracking device attached, they would be aware that any decision to take a side route or stop at the shops or at a friend's house would be knowable to their parents. This may or may not change the path they take, but it potentially changes their awareness of how they move through the spaces on their journey home and what the consequences might be. Without a tracking device, the child would be subject to the usual 'in-the-moment' encounters and interactions, which they would then 
negotiate. The potential future uses of the information collected by surveillance (for example, as the basis for questions or punishment) are also part of the experience in a space of surveillance. These types of possibilities beyond the 'here and now' therefore make the experience of the space different.

A second feature of a space where surveillance is used is that the observer is often (though not always) physically distant or absent. When the observer is not in a co-present, embodied encounter with the child, there is no opportunity for interaction or reciprocity when the surveillance is happening. The parent of the child with a tracking device may discuss the implications with the child before the monitoring begins, but, in general, surveillance is designed to avoid the need for co-presence, and the child often has no knowledge of when they are being observed. In this case, the absence can contribute to the panoptic or self-disciplinary effect discussed earlier. Surveillance is therefore generally a form of watching that allows non-reciprocal access to others by the observers (Patton, 2000, p. 184). Some technologies - such as two-way baby monitors, where a parent can listen and respond to the child from another room - have some scope for interaction, but in these situations the power to initiate interaction is still very much in the hands of the observer, and the child may, in fact, experience this physical absence as the loss of opportunity for co-present interaction. There are examples of people trying to communicate with their observers in a space of surveillance, such as through making gestures to a CCTV camera, and cases where the CCTV controller may respond (Smith, 2007, p. 293), but these are not the equivalent of co-present interactions. In fact, some suggest that the growing opportunity to watch or judge others via distant, technologically mediated encounters means that we are failing to bring the same level of respect and understanding to these encounters compared to if they had happened in person - that is, distant encounters 'neither require nor encourage the same concentration, patience or depth of response that embodied face to face encounters with the commanding presence of the other invites and sometimes demands' (Anderson, 2000, p. 156). An exacerbation of this trend is arguably seen in the prevalence of cyberbullying, where aggressors may 'hide behind the keyboard' or act anonymously in a way that allows them to behave in more hurtful ways than might occur in faceto-face encounters (Mishna et al, 2009, p. 1224). Whether or not surveillance brings challenges or benefits from the fact that the observer is often absent, of significance here is that the space of surveillance can be characterised, in part, by having an observer who is often physically absent or distant, and this brings with it a different experience of that space.

A final feature of a space of surveillance is that it brings new forms of knowledge that would not have otherwise emerged without the surveillance presence. Surveillance is, in this sense, about knowledge production (Monahan \& Torres, 2010, p. 6). As noted earlier, surveillance technologies can capture minute detail, ranging from the precise location of a child to continual recording of a child's activity and behaviour. In this way, a surveillance presence makes possible new forms of knowledge about a particular situation.

Using the notion of the 'data double', it is possible to understand the significance of the new forms of knowledge that may emerge from a 'space of surveillance' for how a child comes to understand themselves and others, and also for how others come to know the child. Consider an incident of conflict or bullying in a school playground captured via CCTV. There are likely to be a range of ways in which the CCTV record could contribute to the handling of the situation. Records captured via CCTV or video are often considered to have an objective or evidentiary status (Pauleit, 2002, p. 477). If the CCTV record comes to be seen as the most reliable or relevant version of the incident and if the technology becomes the focus of attempting to understand what happened or to ascertain the 'truth', there is the potential that other perspectives of the incident (such as the account that might be given by eyewitnesses or a child's emotional response to the event) may be less valued. In this instance, what is recorded as a 'data double' of a child's actions on a CCTV record may be considered to hold more weight or significance than other versions of the event.

As another example, consider the NAPLAN test results of a child. There may be a temptation for teachers, schools, governments and even the students themselves to imbue these results with far more meaning than the 'snapshot' they represent. This is partly due to the power structure or governmental authority behind the collection of the information, which gives it a certain status, but, on a more individual level, in the absence of other information, it is a 'data double' that becomes meaningful because it is sustained over time, persistent, able to be viewed by others, 
compared to others and held in a central register. Even if a child's NAPLAN results are inaccurate, they bring with them ease and potential for the data to be used in a variety of ways that reinforce the data as something significant or 'actual' about the child.

The notion that surveillance technology in some sense reveals the 'truth' makes the records a tempting and ready source to draw on for information about a child's actions, behaviour or progress. This reliance on the technology to show what actually happened, rather than on the stories of children themselves, is starkly illustrated by the following observation by a school principal on the effect of CCTV cameras in his school:

It's like truth serum ... when we have a he-said, she-said situation, 9 times out of 10 all we have to do is ask children if they want us to go back and look at the camera, and they fess up. (Dillon, 2003)

Surveillance therefore brings a new type of data to the negotiation and understanding of complex social scenarios. This data is often sought as the definitive source of knowledge, at times leading it to be viewed as more 'real' or meaningful than alternative versions of events.

Despite the tendency to rely on surveillance records as somehow objective, there is evidence to suggest that the 'knowledge' provided by surveillance records is not always as infallible as it seems. On a practical level, experience shows that what is recorded as our 'data double' (which may include a multitude of information collated about us, not only CCTV footage) is, in fact, often full of errors, fictions and misleading information (Los, 2006, p. 78). There will also always be information outside the field of vision that is not captured.

Surveillance technology is not merely a neutral, static presence in a child's world, but forms part of an active human-technology interface, opening up possibilities and challenges for the child in how they come to understand their place in the world and their relationships with others. When a child's activities are recorded and able to be replayed or used in the future due to a surveillance presence, this can change the emphasis and significance of those activities. It may give certain actions more prominence, distorting the significance of these when compared to actions undertaken in the absence of a surveillance gaze where no such record exists. Even the individual may, in the face of constant review of their data double (or, more accurately, data doubles, for surely there are multiple versions of them), begin to question their own version of a particular event. This shift in emphasis arises simply because the surveillance presence allows actions and encounters to be recorded and replayed (sometimes over and over), creating a particular impression or 'alternative self for the child. It is these characteristics that have led some to observe that, in the era of surveillance: interpersonal acts, even if they take place in the presence of witnesses, are no longer enough to constitute an event. An event ... has only taken place when it has been subjected to a form of video (self) surveillance' (Levin, 2000, quoted in Pauleit, 2002, p. 476).

For the child, if the constant message is that what is captured by an act of surveillance matters more than the child's own perspective of events, then this may challenge the child's own emerging understanding of self and others. Indeed, it may also contribute to how the child comes to understand the very notion of 'truth' or knowledge itself. If the ways a child comes to remember, recall or reflect on their own life become dominated by encounters with various 'data doubles', then a child's view of themselves may be shaped and 'primed' (Schacter, 1996, p. 167) by these records more so than other ways of remembering. A child may even lose the opportunity to forget certain events that they may otherwise have done. The significance of the 'data double' lies therefore in the fact that alternate selves may potentially come to be seen by others as more significant than the real or embodied child. It also lies in how a child comes to understand themselves from their own encounters with various 'data doubles' as these are reinforced or replayed by others.

\section{Concluding Remarks}

Surveillance technologies meet the human child in a way that requires us to interrogate the nature of this relationship and to understand what this means for a child's experience and understanding of their place in the world. In this changing environment, children may confront both new possibilities and potential limitations in spaces where surveillance technologies are present. The 
notion of the 'surveillant assemblage' shows that the interconnections between the child and surveillance technologies are not readily disentangled. As a child becomes open to the possibilities for an emerging sense of selfhood, they may also have to confront a range of other 'reassembled' virtual selves. These have been constructed in spaces that are not neutral, but contain social and political relations of power that influence the shape and potential meaning given to these alternative versions of self.

Contrary to the messages and motivations that often accompany the use of surveillance technologies, the child is not a passive object to be tracked, monitored and eventually 'known' through a single, unitary or static notion of selfhood. Rather, the interdependent and fluid nature of the relationships between children and technologies reveals the complexity of the new spaces that children live within, challenging the ways we come to know the child and how the child comes to know themselves and the very notion of knowledge itself. Children, via a rich and integrated relationship with the technological domain, are fast leading the way to forging new notions of self, identity and relations with others, and, in doing so, contribute to the shaping of the physical-virtual spaces they inhabit. It therefore seems likely that this offers a potent and creative path from which any limited constructions of self that are gleaned from surveillance practices might be challenged and resisted.

\section{Notes}

[1] See Disney’s Club Penguin at http:/ /www.clubpenguin.com/

[2] See Skypito at http:/ / www.skypito.com/

[3] See, for example, NannyCamDirect at http:/ / nannycamdirect.com/

[4] See NurseryCam at http:// www.nurserycam.co.uk/nursery_comments.htm and 'Childcare's Most Trusted Camera System' at https: / /www.watchmegrow.com/

[5] See 'Your Child's Personal GPS Locator' at http:/ / www.amberalertgps.com/ and Child Tracker at http://www.loc8tor.com/uk/childcare

\section{References}

Aitken, S. (2001) Geographies of Young People: the morally contested spaces of identity. London: Routledge.

American Academy of Pediatrics (2011) Policy Statement. Media Use by Children Younger Than 2 Years, Pediatrics, 128(5), 1040-1045. http:// dx.doi.org/10.1542/peds.2011-1753

Anderson, T.C. (2000) The Body and Communities in Cyberspace: a Marcellian analysis, Ethics and Information Technology, 2(3), 153-158. http:/ / dx.doi.org/10.1023/A:1010001504963

Athanasou, J. (2010) NAPLAN and MySchool Survey for the Independent Education Union of Australia. http:/ / www.ieu.org.au/naplan_and_myschool_survey.pdf

Australian Curriculum Assessment and Reporting Authority (2011) NAPLAN - FAQs - General. http:/ / www.nap.edu.au/information/faqs/naplan--general.html

Ball, K., Lyon, D., Wood, D.M., Norris, C. \& Raab, C. (2006) A Report on the Surveillance Society: a report for the Information Commissioner by the Surveillance Studies Network. Information Commissioner's Office'. http://www.surveillance-studies.net/?page_id=3

Bentham, J. (1995) Panopticon of the Inspection House, in M. Bozovic (Ed.) The Panopticon Writings, pp. 29-95. London: Verso.

Buckingham, D. (2007) Childhood in the Age of Global Media, Children's Geographies, 5(1/2), 43-54. http:/ / dx.doi.org/10.1080/14733280601108155

Business Wire (2010) Digital Birth: welcome to the online world, 6 October. http:/ / www.businesswire.com/news/home/20101006006722/en/Digital-Birth-Online-World

Cleland, K. (2010) Prosthetic Bodies and Virtual Cyborgs, Second Nature, 3, 74-101.

Deleuze, G. \& Guattari, F. (1988) A Thousand Plateaus: capitalism and schizophrenia II. London: Athlone Press.

Dillon, S. (2003) Cameras Watching Students, Especially in Biloxi, New York Times, 24 September.

Foucault, M. (1991) Discipline and Punish: the birth of the prison. London: Penguin.

Freeman, C. \& Tranter, P.J. (2011) Children and Their Urban Environment: changing worlds. London: Earthscan. 
Gilliom, J. (2010) Lying, Cheating and Teaching to the Test, in T. Monahan \& R.D. Torres (Eds) Schools under Surveillance: cultures of control in public education, pp. 194-209. New Brunswick, NJ: Rutgers University Press.

Haggerty, K.D. \& Ericson, R.V. (2000) The Surveillant Assemblage, British Journal of Sociology, 51(4), 605-622. http: / / dx.doi.org/10.1080/00071310020015280

Independent (2011) Children's Gaming and Social Networking Site Hits 50 Million Users, 8 June. http: / / www.independent.co.uk/life-style/ gadgets-and-tech/ childrens-gaming-and-social-networkingsite-hits-50-million-users-2294604.html

Katz, C. (2006) The State Goes Home: local hypervigilance of children and the global retreat from social reproduction, in T. Monahan (Ed.) Surveillance and Security: technological politics and power in everyday life. New York: Routledge.

Koskela, H. (2004) Webcams, TV Shows and Mobile Phones: empowering exhibitionism, Surveillance and Society, 2(2/3), 199-215.

Los, M. (2006) Looking into the Future: surveillance, globalization and the totalitarian potential, in D. Lyon (Ed.) Theorizing Surveillance: the panopticon and beyond. Cullompton: Willan.

Louv, R. (2005) Last Child in the Woods: saving our children from nature-deficit disorder. Chapel Hill, NC: Algonquin Books.

Luckerson, V. (2012) Should You Use Your Smart Phone to Track Your Kids? Time, 14 September. http: / / business.time.com/2012/09/14/should-you-use-your-smartphone-to-track-your-kids /

Lyon, D. (2001) Surveillance Society: monitoring everyday life. Buckingham: Open University Press.

Lyon, D. (Ed.) (2003) Surveillance as Social Sorting: privacy, risk and digital discrimination. London: Routledge.

Lyon, D. (Ed.) (2006) Theorizing Surveillance: the panopticon and beyond. Cullompton: Willan.

Malone, K. (2007) The Bubble-wrap Generation: children growing up in walled gardens, Environmental Education Research, 13(4), 513-527. http:/ / dx.doi.org/10.1080/13504620701581612

Marsh, J., Brooks, G., Hughes, J., Ritchie, L., Roberts, S. \& Wright, K. (2005) Digital Beginnings: young children's use of popular culture, media and new technologies. Sheffield: Literacy Research Centre, University of Sheffield. http:/ / dx.doi.org/10.4324/9780203420324

Massey, D. (2005) For Space. London: Sage.

McClure, R. (n.d.) Before You Consider Using In-home Surveillance, About.com, Child Care. http:/ / childcare.about.com/cs/evaluations/bb/nannycam.htm

Mishna, F., Saini, M. \& Solomon, S. (2009) Ongoing and Online: children and youth's perceptions of cyber bullying, Children and Youth Services Review, 31(12), 1222-1228. http: / / dx.doi.org/10.1016/j.childyouth.2009.05.004

Monahan, T. \& Torres, R.D. (Eds) (2010) Schools under Surveillance: cultures of control in public education. New Brunswick, NJ: Rutgers University Press.

Nadesan, M.H. (2010) Governing Childhood into the 21st Century: biopolitical technologies of childhood management and education. New York: Palgrave Macmillan. http: / / dx.doi.org/ 10.1057/9780230106499

Patton, J.W. (2000) Protecting Privacy in Public? Surveillance Technologies and the Value of Public Places, Ethics and Information Technology, 2(3), 181-187. http: / dx.doi.org/10.1023/ A:1010057606781

Pauleit, W. (2002) Video Surveillance and Postmodern Subjects: the effects of the photographesomenon - an image-form in the 'futur antérieur', in T.Y. Levin, U. Frohne \& P. Weibel (Eds) Ctrl [Space]: rhetorics of surveillance from Bentham to Big Brother. Karlsruhe: ZKM Center for Art and Media \& MIT Press.

Plowman, L., Stephen, C. \& McPake, J. (2010) Growing Up with Technology: young children learning in a digital world. London: Routledge.

Prout, A. (2005) The Future of Childhood: towards the interdisciplinary study of children. London: Routledge.

Rooney, T. (2010) Trusting Children: how do surveillance technologies alter a child's experience of trust, risk and responsibility? Surveillance and Society, 7(3/4), 344-355.

Schacter, D. (1996) Searching for Memory: the brain, the mind and the past. New York: Basic Books.

Smith, G.J.D. (2007) Exploring Relations between Watchers and Watched in Control(led) Systems: strategies and tactics, Surveillance and Society, 4(4), 280-313.

Steeves, V. (2010) Online Surveillance in Canadian Schools, in T. Monahan \& R.D. Torres (Eds) Schools under Surveillance: cultures of control in public education, pp. 87-103. New Brunswick, NJ: Rutgers University Press.

Stevenson, A. (2012) Debate Rages as Students Sit NAPLAN, Sydney Morning Herald, 15 May. http:/ / www.smh.com.au/national/ education/ debate-rages-as-students-sit-naplan-20120514-1yn06.html 


\section{Tonya Rooney}

Taylor, E. (2010) I Spy with My Little Eye: the use of CCTV in schools and the impact on privacy, Sociological Review, 58(3), 381-405. http:// dx.doi.org/10.1111/j.1467-954X.2010.01930.x

Valentine, G. (2000) Transforming Cyberspace: children's interventions in the new public sphere, in S. Holloway \& G. Valentine (Eds) Children's Geographies: playing, living, learning. London: Routledge.

Valentine, G. (2004) Public Space and the Culture of Childhood. Aldershot: Ashgate.

Yelland, N. (2007) Shift to the Future: re-thinking learning with new technologies in education. New York: Routledge.

TONYA ROONEY is an Adjunct Professional Associate with the Childhood Research Collective, Faculty of Education, University of Canberra. Correspondence: tonya.rooney@canberra.edu.au 